\title{
Extracorporeal Membrane Oxygenation in Extreme Obesity: A Case Report and Review of the Literature
}

\author{
Vitali Azouz, MD,${ }^{1}$ Sarah Hill, $M D,{ }^{2}$ Michael S. Firstenberg, MD $^{2,3}$ \\ ${ }^{1}$ Department of Surgery, Summa Akron City Hospital, Akron, OH; ${ }^{2}$ Northeast Ohio Medical Universities, Rootstown, OH; \\ ${ }^{3}$ Department of Surgery, The Medical Center of Aurora, Aurora, CO
}

\section{INTRODUCTION}

The use of extracorporeal membrane oxygenation $(\mathrm{ECMO})$ in the treatment of acute respiratory distress syndrome (ARDS) has been described as early as 1972 [Hill 1972]. Though a subsequent randomized trial showed no survival benefit over conventional mechanical ventilation [Zapol 1979], protective ventilation strategies and evolving extracorporeal technology improvements have led to a resurgence in the use of ECMO for patients with ARDS. The most recent randomized clinical trial, Conventional Ventilation or ECMO for Severe Adult Respiratory Failure (CESAR), showed a significant mortality reduction in ARDS patients who were treated with ECMO [Peek 2009]. The results of the trial have led some to believe that the widespread adoption of ECMO as a feasible treatment for severe respiratory failure is forthcoming [MacLaren 2012; Del Sorbo 2014]. As the use of ECMO continues to increase, clinicians must be aware of the extremes in patient characteristics for which therapy might be considered reasonable. For example, many studies focus on the limited benefit of advanced therapies, such as ECMO, in the elderly [Salna 2014]. However, there is a paucity of literature on using veno-venous extracorporeal membrane oxygenation (VV ECMO) to treat ARDS in patients with extremity obesity [Ull 2015; Belliato 2016; Kadakia 2017]—a population that is often inherently discriminated against with regards to advanced medical and surgical therapies because of the practical challenges of treating someone of great size as well as the inherent social (and professional) biases against such patients. This case demonstrates application of ECMO in a patient with an extreme body mass index (BMI) and confirms the successful use of ECMO in this BMI patient population.

\section{CASE REPORT}

A 38-year-old female with a BMI of $82(228.8 \mathrm{~kg}, 167$ $\mathrm{cm}$ ) presented to an outside hospital with a chief complaint of abdominal pain and shortness of breath. Her past medical

Received fune 3, 2018; accepted September 28, 2018.

The therapies and technologies described in this case report have not been approved by the United States Food and Drug Administration for long-term use.

Vitali Azouz MD, Department of Surgery, Summa Health System, 55 Arch Street, Suite 2F, Akron, OH 44304-1423; 1-330-375-3783; (Azouzv@ summabealth.org). history was significant for depression, hypertension, hypothyroidism, anxiety, and obstructive sleep apnea. Shortly after presentation, she developed respiratory distress and required mechanical ventilation and initiation of broadspectrum antibiotics. The CT scanner at the outside facility could not accommodate her body habitus, so she was transferred to Summa Health, Akron City Hospital. CT scanning at our institution demonstrated small bilateral pleural effusions with diffuse bilateral consolidation of bilateral lower lobes and right middle lobe. No intra-abdominal abnormality or pulmonary thrombolic disease was identified. Despite maximal ventilation therapies including fraction of inspired oxygen $\left(\mathrm{FiO}_{2}\right)$ of $100 \%$, bilevel ventilation $40 / 16$ (high/low pressures), and a rate of 16 , the patient's condition continued to rapidly deteriorate with a Murray core of 3.75 [Murray 1988]. Arterial blood gas indicated a $\mathrm{pH}=7.43, \mathrm{PCO}_{2}=50.4$, $\mathrm{PO}_{2}=55$, base excess of +10 , with a saturation of $89 \%$; and chest $\mathrm{x}$-ray was worrisome for severe ARDS (Figure 1).

Several hours earlier, her $\mathrm{PCO}_{2}$ was 51.1, and her $\mathrm{PO}_{2}$ was $136 \mathrm{mmHg}$. This prompted immediate discussions regarding the appropriateness for ECMO. Despite her size, and in light of her rapid deterioration (with the hope that she had a reversible problem) and her few baseline comorbidities, it was felt that she might benefit from ECMO. Written informed consent was obtained for ECMO cannulation and

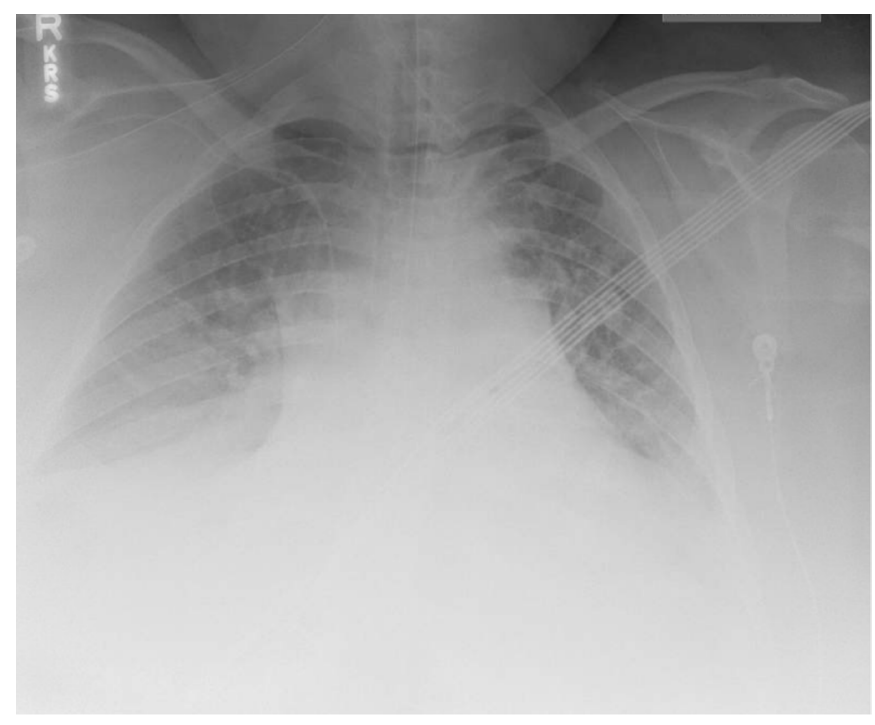

Figure 1. Chest x-ray before ECMO cannulation. 


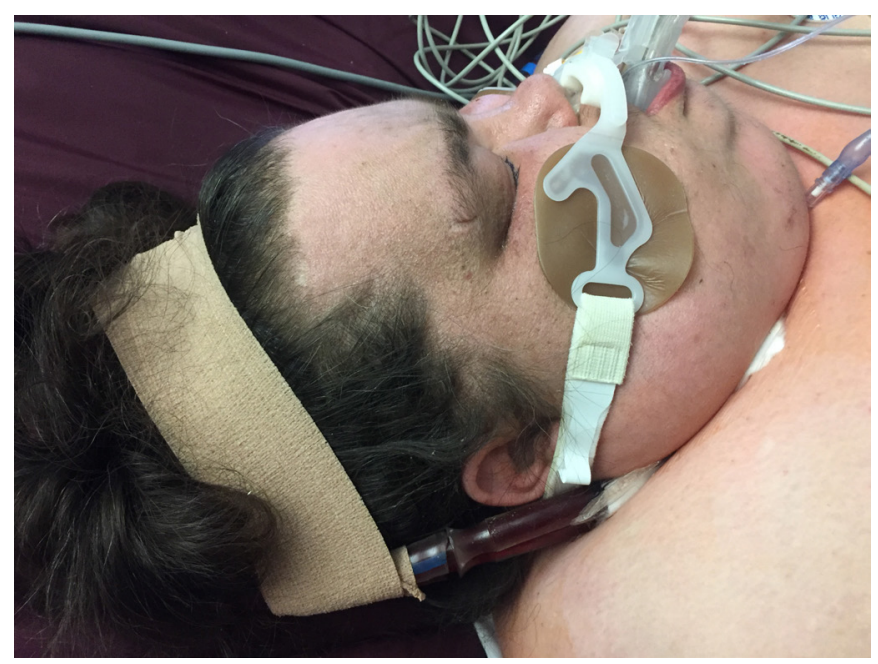

Figure 2. Picture demonstrating ECMO cannula coming from right neck.

support - and for the use of her clinical information, findings, and images for educational purposes. She was subsequently taken to the operating room for cannulation for VV ECMO. The presumed diagnosis was ARDS secondary to aspiration pneumonia.

Prior to taking her to the operating room, as the operating team (ie, surgeon, anesthesia, nursing, perfusionist) was being mobilized, the following was performed. For the purpose of facilitating safe cannulation, ultrasound guidance was used to place a right internal jugular central line. Proper positioning of the line was confirmed with a portable chest $x$-ray. In the operating room, the patient was left on her hospital/ ICU bed. Because of her extreme size and potentially chronically infected groins, it was felt that cannulation with a duallumen ECMO cannula was the optimal approach. Following heparinization (10,000 units, IV heparin that was allowed to circulate for 3 minutes), the tract was then dilated by using the Seldinger technique to accommodate a 27-F Avalon dual-lumen ECMO cannula (Maquet Cardiovascular LLC, Wayne, NJ, USA). The circuit was de-aired and connected to the ECMO circuit (Cardiohelp, Maquet Cardiovascular LLC). The cannula was positioned by using transesophageal ultrasound guidance to direct inflow over across the tricuspid valve [Javidfar 2011]. Once positioned properly, the line was sutured in place to limit potential migration in cranial, caudal, or malrotation ways (Figure 2).

Initial ECMO flows were 3.2 liters/minute, $3460 \mathrm{rpm}$, $100 \%$ oxygen, and a gas sweep of 2.5 . This led to a significant improvement in overall oxygenation and ventilation and in the ability to adjust the ventilator to achieve a lung-protective strategy. Following successful cannulation, bronchoscopy with bronchoalveolar lavage was performed. She tolerated the procedure and returned back to the ICU. Anticoagulation management consisted of intravenous heparin, titrated to a PTT of 40-60 seconds. Subsequent respiratory cultures grew Staphylococcus aureus antibiotics that were tailored according to sensitivities. Despite significant improvement in her oxygenation and ventilation with minimal ventilator settings, it was felt that her chest wall mechanics and abdominal obesity would preclude a safe and timely extubation. Hence, on postoperative day 7 the patient underwent open tracheostomy for respiratory support in anticipation of decannulation, which occurred 2 days later. Decannulation was performed at the bedside, in the ICU, and consisted of discontinuing anticoagulation for several hours, placing a purse-string suture around the cannula as it entered into her neck, pulling the cannula, tying the suture, holding pressure for several minutes, and applying a sterile dressing. The procedure was performed with the patient sedated and in the upright position with careful attention to limit the risk of an air embolism; and after removal, a weighted sandbag was placed against her neck and supported by her shoulder to apply pressure on the cannulation site to limit potential bleeding. The reminder of her hospital stay was uneventful as she completed a 14-day course of antibiotics. The patient was discharged to a long-term care facility on hospital day 16 with minimal respiratory support. A percutaneous endoscopic feeding tube (PEG) was placed for nutritional support. At 6-months follow-up, she was successfully weaned from her chronic tracheostomy, she had preserved end-organ and intact neurologic function and was able to return to her community and pre-illness living conditions.

\section{DISCUSSION}

Obesity has been identified as a risk factor for the development of ARDS that manifests as a weight-dependent relationship, the greater a patient's weight the higher the risk for developing ARDS [Gong 2010]. Though VV ECMO has been shown to be effective in the treatment of ARDS [Peek 2009; Lancet 2012; Del Sorbo 2014], few studies and case reports have investigated its use in patients whose BMI surpasses 80 [Ull 2015; Kadakia2017].

Mongero et al were first to report the successful use of $\mathrm{VV}$ ECMO to treat ARDS in 2 patients with BMIs of 52 and 58 [Mongero 2006]. In their report, the authors recommended gaining access by using a groin incision for venous exposure and cannulating through a separate stab wound to allow wound closure and percutaneous removal. They also recommended using pressure control ventilation and permissive hypercapnia while using ECMO. In their analysis of the Extracorporeal Life Support Organization (ELSO) database, Al-Soufi et al found that increased body weight was not a risk factor for hospital mortality in patients requiring VV ECMO. Because body height was not recorded in the database, the authors used body weight to conclude that high body weight was not a contraindication to VV ECMO [Al-Soufi 2013]. However, the range of body weights in the study of Al-Soufi et al was $25-251 \mathrm{~kg}$. This claim was further substantiated by studies that showed that BMI >30 [Lazzeri 2017] and BMI $>40$ [Kon 2015] are not associated with poorer outcomes in patients on VV ECMO. Another small, single-center retrospective study sought to define whether obese patients experience worse outcomes following extracorporeal device (ECD) support, consisting of either VV ECMO or pump-less extracorporeal lung assist (pECLA). No significant association was found between obesity and ICU length of stay, hospital length 
of stay, ECD run time, or in-hospital mortality. Because the majority of patients had traumatic etiology and the median patient BMI was 30, the application to the extremely obese population is limited [Swol 2017].

\section{CHALLENGES OF VV ECMO IN THE OBESE} PATIENT

Obesity is associated with increased pulmonary resistance and increased cardiac output, which may surpass ECMO's oxygenation capability [Schmidt 2013]. Additionally, morbid obesity is associated with increased oxygen consumption for respiratory work [Kress 1999],upper airway resistance, chronic ventilation-perfusion mismatch, and hypoxemia [Shashaty 2014]. Obese patients are often also at risk for chronic hypoventilation, obstructive sleep apnea, pulmonary hypertension, and right ventricular dysfunction-all characteristics that predispose them to both acute and chronic respiratory management challenges. Patients who are extremely obese with $\mathrm{BMI}>80$ present with a variety of challenges to be considered during the initiation and maintenance of $\mathrm{VV}$ ECMO. Because of alterations in patient anatomy and difficulty visualizing anatomic landmarks (even with ultrasound guidance), vascular cannulation may be technically challenging - regardless of the cannulation strategy-and inherently dangerous. Additionally, bulky soft tissue may cause kinking of lines and increases the risk of bleeding if multiple attempts at cannulation are performed. Although initial experiences with dual-lumen cannulation were described as having a significant risk for catastrophic vascular access complications (such as great vessel and cardiac structure injuries resulting in tamponade and death), other than operator experience, little is known about patient risks for vascular complications during dual-lumen catheter placement. Such well-described injuries and difficulties in cannula positioning and management are often used as justification for the use of alternative vascular cannulation sites and technologies-such as femoral cannulation with 2 opposite single-lumen cannulas - which, as a function of their size can often provide great flows with smaller individual lumen sizes [Camboni 2012]. Obese patients also often require cannulation of the groin because of inadequate visualization of cervical vessels with ultrasound. Single-lumen cannulas are often used (ie, bilateral femoral vein cannulation) because they are believed to allow for increased ECMO circuit flows-a theoretical advantage in patients who might be septic and need increased oxygenation of their blood. This may place patients at increased risk of line infection, skin break-down, ulceration, and possible sepsis-especially if the groin regions have existing baseline skin integrity compromise or chronic infectious colonization as is typically encountered with morbidly obese patients. In addition, these patients can be inherently difficult to manage from a nursing or wound care perspective, independently of the use of ECMO, and may predispose to a worsening of existing chronic problems during times of acute illness, especially during periods of impaired tissue perfusion and oxygenation as is encountered during respiratory failure [Yaegashi 2005]. Mechanical complications may also occur, such as difficulty or failure to maintain adequate flow and minute volume because of compression of the inferior vena cava (IVC) by intra-abdominal adipose tissue [Fischer 2016].

Our patient underwent successful cannulation by use of a 27-F dual-lumen catheter that was placed in the internal jugular vein under transesophageal ultrasound. Based upon the design of these cannulas, the tip of the catheter was angled by using transesophageal ultrasound to maintain flow through the tricuspid valve. Though cannulation may be technically challenging, $\mathrm{BMI}>80$ is not a contraindication to using $\mathrm{VV}$ $\mathrm{ECMO}$ in this patient population. Once recovery occurs, decannulation can be successfully performed at the bedside, but long-term weaning from the ventilator should be anticipated in this inherently chronically pulmonary-compromised patient population. With growing widespread use and success of ECMO, hopefully cases such as ours, and further studies, can help define the limits in which this advanced therapy might be considered appropriate.

\section{ACKNOWLEDGMENTS}

Financial disclosures: S.H. and V.A. have no disclosures. M.S.F. serves as a technical consultant and receives education honorariums ( $<\$ 5,000 /$ year) from Maquet Cardiovascular.

\section{REFERENCES}

Al-Soufi S, Buscher H, Nguyen ND, Rycus P, Nair P. 2013. Lack of association between body weight and mortality in patients on venovenous extracorporeal membrane oxygenation. Intensive Care Med 39:1995-2002

Belliato M, Cremascoli L, Aliberti A, Pagani M, Pellegrini C, Iotti GA. 2016. A case of veno-venous extracorporeal membrane oxygenation for severe respiratory failure in a superobese patient. Clin Case Rep 4:1147-50.

Camboni D, Philipp A, Lubnow M, et al. 2012. Extracorporeal membrane oxygenation by single-vessel access in adults: advantages and limitations. ASAIO J 58:616-21.

Del Sorbo L, Cypel M, Fan E. 2014. Extracorporeal life support for adults with severe acute respiratory failure. Lancet Respir Med 2:154-64.

Fischer AJ, Kaese S, Lebiedz P. 2016. Management of obese patients with respiratory failure - A practical approach to a health care issue of increasing significance. Respir Med 117:174-8.

Gong MN1, Bajwa EK, Thompson BT, Christiani DC. 2010. Body mass index is associated with the development of acute respiratory distress syndrome. Thorax 65:44-50.

Hill JD, O’Brien TG, Murray JJ, et al. 1972. Prolonged extracorporeal oxygenation for acute post-traumatic respiratory failure (shock-lung syndrome). Use of the Bramson membrane lung. N Engl J Med. 286:629-34.

Javidfar J, Wang D, Zwischenberger JB, et al. 2011. Insertion of bicaval dual lumen extracorporeal membrane oxygenation catheter with image guidance. ASAIO J 57:203-5.

Kadakia S, Ambur V, Moore R, Toyoda Y, Shiose A. 2017. Venovenous extracorporeal membrane oxygenation in two morbidly obese patients. Gen Thorac Cardiovasc Surg 65(10):594-7.

Kon ZN, Dahi S, Evans CF, et al. 2015. Class III obesity is not a contraindication to venovenous extracorporeal membrane oxygenation support. Ann Thorac Surg 100:1855-60. 
Kress JP, Pohlman AS, Alverdy J, Hall JB. 1999. The impact of morbid obesity on oxygen cost of breathing $\left(\mathrm{V}^{\circ} \mathrm{O}_{2 \mathrm{RESP}}\right)$ at rest. Am J Respir Crit Care Med 160:883-6.

Lazzeri C, Bonizzoli M, Cianchi G, et al. 2017. Body mass index and echocardiography in refractory ARDS treated with veno-venous extracorporeal membrane oxygenation. J Artif Organs 20:50-6.

MacLaren G, Combes A, Bartlett RH. 2012. Contemporary extracorporeal membrane oxygenation for adult respiratory failure: life support in the new era. Intensive Care Med 38:210-20.

Mongero LB, Beck JR, Charette KA, Stewart A. 2006. Respiratory failure of two sp gastric bypass patients and subsequent rescue with extracorporeal membrane oxygenation. Perfusion 21:73-6.

Murray JF, Matthay MA, Luce JM, Flick MR. 1988. An expanded definition of the adult respiratory distress syndrome. Am Rev Respir Dis 138:720-3.

Peek GJ, Mugford M, Tiruvoipati R, et al. 2009. Efficacy and economic assessment of conventional ventilatory support versus extracorporeal membrane oxygenation for severe adult respiratory failure (CESAR): a multicentre randomised controlled trial. Lancet 374:1351-63.

Salna M, Takeda K, Kurlansky P, et al. 2018. The influence of advanced age on venous-arterial extracorporeal membrane oxygenation outcomes. Eur J Cardiothorac Surg 53:1151-7.

Schmidt M, Tachon G, Devilliers C, et al. 2013. Blood oxygenation and decarboxylation determinants during venovenous ECMO for respiratory failure in adults. Intensive Care Med 39:838-46.

Shashaty MG, Stapleton RD. 2014. Physiological and management implications of obesity in critical illness. Ann Am Thorac Soc 11:1286-97.

Swol J, Buchwald D, Strauch JT, Schildhauer TA, Ull C. 2017. Effect of body mass index on the outcome of surgical patients receiving extracorporeal devices (VV ECMO, pECLA) for respiratory failure. Int J Artif Organs 40:102-8.

Ull C, Buchwald D, Strauch J, Schildhauer TA, Swol, J. 2015. Extremely obese patients treated with venovenous ECMO-an intensivist's challenge. Am J Emerg Med 33:1720.e3-1720.e4.

Zapol WM, Snider MT, Hill JD, et al. 1979. Extracorporeal membrane oxygenation in severe acute respiratory failure: a randomized prospective study. JAMA 242:2193-6.

Yaegashi M, Jean R, Zuriqat M, Noack S, Homel P. 2005. Outcome of morbid obesity in the intensive care unit. J Intensive Care Med 20:147-54. 